\title{
A novel urinary biomarker predicts 1-year mortality after discharge from intensive care
}

Esther Nkuipou-Kenfack' ${ }^{1}$, Agnieszka Latosinska' ${ }^{1}$ Wen-Yi Yang ${ }^{2,3}$, Marie-Céline Fournier ${ }^{4}$, Alice Blet ${ }^{4,5}$, Blerim Mujaj ${ }^{2}$, Lutgarde Thijs ${ }^{2}$, Elodie Feliot ${ }^{4}$, Etienne Gayat ${ }^{4,5,6}$, Harald Mischak', Jan A. Staessen ${ }^{2,7}$, Alexandre Mebazaa ${ }^{4,5,6}$, Zhen-Yu Zhang ${ }^{2^{*}}$ (I) and The French and European Outcome Registry in Intensive Care Unit Investigators

\begin{abstract}
Rationale: The urinary proteome reflects molecular drivers of disease.

Objectives: To construct a urinary proteomic biomarker predicting 1-year post-ICU mortality.

Methods: In 1243 patients, the urinary proteome was measured on ICU admission, using capillary electrophoresis coupled with mass spectrometry along with clinical variables, circulating biomarkers (BNP, hsTnT, active ADM, and NGAL), and urinary albumin. Methods included support vector modeling to construct the classifier, Cox regression, the integrated discrimination (IDI), and net reclassification (NRI) improvement, and area under the curve (AUC) to assess predictive accuracy, and Proteasix and protein-proteome interactome analyses.
\end{abstract}

Measurements and main results: In the discovery (deaths/survivors, 70/299) and test (175/699) datasets, the new classifier ACM128, mainly consisting of collagen fragments, yielding AUCs of 0.755 (95\% Cl, 0.708-0.798) and 0.688 (0.656-0.719), respectively. While accounting for study site and clinical risk factors, hazard ratios in 1243 patients were 2.41 (2.00-2.91) for ACM128 (+ 1 SD), 1.24 (1.16-1.32) for the Charlson Comorbidity Index (+ 1 point), and $\geq$ $1.19(P \leq 0.022)$ for other biomarkers ( +1 SD). ACM128 improved $(P \leq 0.0001)$ IDI $(\geq+0.50)$, NRI $(\geq+53.7)$, and AUC $(\geq+0.037)$ over and beyond clinical risk indicators and other biomarkers. Interactome mapping, using parental proteins derived from sequenced peptides included in ACM128 and in silico predicted proteases, including/ excluding urinary collagen fragments (63/35 peptides), revealed as top molecular pathways protein digestion and absorption, lysosomal activity, and apoptosis.

Conclusions: The urinary proteomic classifier ACM128 predicts the 1-year post-ICU mortality over and beyond clinical risk factors and other biomarkers and revealed molecular pathways potentially contributing to a fatal outcome.

Keywords: Biomarker, Intensive care medicine, Heart failure, Mortality, Urinary proteomics

\footnotetext{
* Correspondence: zhenyu.zhang@kuleuven.be

This article has an online supplement, which is accessible from this issue's table of contents at www.atsjournals.org.

${ }^{2}$ Studies Coordinating Centre, Research Unit Hypertension and

Cardiovascular Epidemiology, KU Leuven Department of Cardiovascular

Sciences, University of Leuven, Campus Sint Rafaël, Kapucijnenvoer 35, Box

7001, 3000 Leuven, Belgium

Full list of author information is available at the end of the article
}

(c) The Author(s). 2020 Open Access This article is distributed under the terms of the Creative Commons Attribution 4.0 International License (http://creativecommons.org/licenses/by/4.0/), which permits unrestricted use, distribution, and reproduction in any medium, provided you give appropriate credit to the original author(s) and the source, provide a link to the Creative Commons license, and indicate if changes were made. The Creative Commons Public Domain Dedication waiver (http://creativecommons.org/publicdomain/zero/1.0/) applies to the data made available in this article, unless otherwise stated. 


\section{Introduction}

In high- and middle-income countries, millions of patients survive critical illness thanks to the highly specialized lifesustaining management in intensive care units (ICU). However, cumulative mortality over the first year after ICU discharge ranges from 26 to 63\% [1]. Large cohort studies conducted in Canada [2], Australia [3], and the USA [1] demonstrated that ICU survivors followed up from 3 [1, 2] up to 15 [3] years experienced mortality rates 2 to 5 times higher than sex- and age-matched population controls. The number of patients who survive intensive care is growing fast, because of the demographic transition in aging populations [4] and the ongoing sophistication of critical care resulting in a lower in-ICU fatality rate [5-7]. Several risk factors determine the 1-year risk of death after ICU discharge. Clinical risk indicators include older age, the indication for critical care, comorbidities, the number of failing organs, the length of ICU care, and newly diagnosed malignancies [3]. The risk of death is also associated with circulating and urinary biomarkers indicative of myocardial, vascular, or renal distress [8]. Stakeholder conferences advised prioritizing research on reliable predictors of post-ICU impairments and death to identify patients in need of further diagnostic work-up and targeted treatment $[5,7]$. Urinary proteomic profiling developed over the past 15 years into a state-of-the-art technology, which enables discovery of disease-specific multidimensional biomarkers indicative of molecular pathogenic processes $[9,10]$. Along these lines, the current study aimed to develop a urinary proteomic classifier predictive of the 1-year mortality in ICU survivors. The French and European Outcome Registry in Intensive Care Unit Investigators (FROG-ICU; (NCT01367093) compiled the analyzed database $[8,11]$.

\section{Methods}

\section{Patients}

FROG-ICU involved medical, surgical, or mixed ICUs at 15 university hospitals [11]. Inclusion criteria included mechanical ventilation or administration of vasoactive agents for at least $24 \mathrm{~h}$. The exclusion criteria were age less than 18 years, severe head injury with a Glasgow Coma Scale [12] below 8, brain death or persistent vegetative state, pregnancy or breastfeeding, transplantation in the past 12 months, moribund status, and lack of social security coverage [11].

\section{Measurements}

Anthropometric, clinical, and routine biochemical data were recorded on ICU admission. Variables of interest included the indication for admission to the ICU, the Charlson Comorbidity Index (CCI) [13, 14], the Sequential Organ Failure Assessment (SOFA) [15] score, blood pressure, serum creatinine and cystatin $\mathrm{C}$, and blood glucose. Information also collected on admission, included treatment with mechanical ventilation, extracorporeal membrane oxygenation, or renal replacement therapy.

The CCI is a method of categorizing comorbidities of patients based on the International Classification of Diseases (ICD) diagnosis codes found in administrative data. It included 19 categories (Additional file 1: Table S1). Each comorbidity category has an associated weight (from 1 to 6), based on the adjusted risk of mortality or resource use, and the sum of all the weights results in a single comorbidity score for a patient. A CCI was calculated for each patient on ICU admission to classify comorbidity and grouped as having either no comorbidity $(\mathrm{CCI}=0)$, moderate comorbidity $(\mathrm{CCI}=1-5)$, or severe comorbidity $(\mathrm{CCI} \geq 6)$. SOFA score can help assess the degree of organ dysfunction on ICU admission. The score is based on six different scores, one each for the respiratory, cardiovascular, hepatic, coagulation, renal, and neurological systems. If an organ is not affected, a zero score is given. If an organ system is affected in multiple ways, the highest score is used in constructing the SOFA categorization. SOFA scores range from 0 to 24 , and the risk of death is proportional to the score.

Estimated glomerular filtration rate was derived from serum creatinine $\left(e G F R_{\text {crt }}\right)$ or cystatin $C\left(e G F R_{\text {cys }}\right)$, according to the Chronic Kidney Disease Epidemiology Collaboration equation [16]. Fresh urine samples were analyzed for the albumin concentration.

\section{Biomarkers}

Circulating and urinary biomarkers were measured in a central certified laboratory on samples obtained on ICU admission. The circulating biomarkers indicated left ventricular dysfunction (brain natriuretic peptide [BNP]; Roche Diagnostics GmbH, Mannheim, Germany), left ventricular ischemia and injury (high-sensitive troponin T [hsTNT]; Abbott, Abbott Park, IL) [17], myocardial ischemia (high-sensitive troponin I [hsTnI]; Abbott, Abbott Park, IL) [18], vascular dysfunction (biologically active adrenomedullin [ADM]; Adrenomed $\mathrm{GmbH}$, Hennigsdorf, Germany) [19], inflammation and cardiac stress (the interleukin-1 receptor family member soluble ST2 [sST2]; Eurobio, Critical Diagnostics, San Diego, CA) [20], or acute kidney injury (neutrophil-gelatinase-associated lipocalin [NGAL]; ARCHITECT, Abbott Diagnostics, Chicago, IL) [21]. The urinary biomarkers included albuminuria and NGAL [21].

The urinary proteome is well characterized, and reference standards are available [22]. Urine proteome analysis was performed on urine samples collected on admission and bio-banked until assayed. Detailed information on urine sample preparation, proteome analysis by capillary electrophoresis coupled to mass spectrometry, data processing, and sequencing of the urinary 
peptides allowing identification of parent proteins is available in previous publications [9] and the methods section of the online-only supplement.

\section{Outcome}

Information on vital status was collected 3, 6, and 12 months after ICU discharge, as previously described [11]. Trained clinical research assistants called the patients or their relatives. The short intervals between contacts, ranging from 3 to 6 months, established a strong relationship of trust between the research team, the patients, and their family. If this direct contact was lost during follow-up, vital status was ascertained via national health services records. For the current study, the 1-year vital status was known for all patients included in the analysis.

\section{Statistics}

SAS, version 9.4, maintenance level 5 (SAS Institute Inc., Cary, NC) was used for database management and statistical analysis. Departure of distributions from normality was evaluated by the Shapiro-Wilk test. The biomarker distributions with the exception of ACM128 were transformed by sorting measurements from the smallest to the highest and then applying the inverse cumulative normal function [23]. Means, medians, and proportions were compared using the large-sample $z$-test or ANOVA, the Wilcoxon rank-sum test, and Fisher's exact test, respectively. We computed $95 \%$ confidence interval of rates as $R \pm 1.96 \times \sqrt{(R / T)}$, where $R$ and $T$ are the rate and the denominator used to calculate the rate.

\section{Construction and initial validation of the classifier}

For discovery of the new classifier associated with allcause mortality following ICU discharge, $30 \%$ of the cohort (299 survivors and 70 nonsurvivors) were randomly selected from all enrolled patients $(n=1243)$. For validation, the remainder of the cohort was analyzed (699 survivors and 175 nonsurvivors). In the discovery phase, the association of mortality with urinary peptides was assessed by Wilcoxon testing targeting a significance level of 0.05 . The peptides that remained associated with the 1-year mortality were combined into a single multidimensional classifier, using support vector machine modeling, as implemented in the MosaCluster software, version 1.7.0, and as described in detail in the methods section of the online supplement.

\section{Performance of the classifier}

In patients included in the validation data set, performance of the new classifier was assessed, using proportional hazards regression. The comparators were established clinical predictors of adverse health outcomes in ICU patients, i.e., the Charlson Comorbidity Index [13, 14] and SOFA [15] score and other circulating and urinary biomarkers. These analyses accounted for center effects as a random variable and for risk factors as fixed effects. Centers were grouped per location $(n=15)$ or per group of patients they were serving (medical, surgical, or mixed). First, cumulative incidence of death was plotted by thirds of the distribution of the new classifier, while accounting for sex, age, and Charlson Comorbidity Index. Next, the hazard ratios relating the risk of death to tertiles of classifier were computed from Cox models adjusted for sex, age, mean arterial pressure (diastolic pressure plus one third of pulse pressure), eGFR, and diabetes mellitus. The proportional hazards assumption was checked by the Kolmogorov-type supremum test and by testing the interaction between follow-up duration and the new classifier. Finally, in multivariable-adjusted Cox models, the accuracy of the classifier to discriminate between survivors and nonsurvivors was compared with the Charlson Comorbidity Index [13] and other biomarkers (one at a time). Improvement in model performance was assessed from the integrated discrimination improvement (IDI) [24], the net reclassification improvement (NRI) [24], and the change in the area under the curve $(\Delta \mathrm{UC})$.

\section{Analysis of single urinary peptides}

For analysis of single peptides, sequenced peptides, which had a detectable signal in over $70 \%$ of participants, were selected. $P$ values and confidence intervals were adjusted for multiple testing using the Bonferroni method based on the number of parental proteins identified.

\section{Proteasix and pathway analysis}

Proteases responsible for the generation of the urinary peptide fragments were predicted in silico, using Proteasix $[25,26]$. Proteolytic enzymes mapped to at least 10 cleavage sites in the peptides associated with post-ICU mortality were analyzed. The protein-protein interactome was constructed, using the STRING database (STRING, version 11.0; https://string-db.org). Proteins corresponding to sequenced urinary peptides and the in silico predicted proteolytic enzymes were included for the interactome analysis. The pathway enrichment was evaluated against the Kyoto Encyclopedia of Genes and Genomes (KEGG) database with the false discovery rate set at $P<0.01$.

Changes in urinary collagen fragments might reflect alterations in protease activity, but may also be the result of a change in collagen turnover in tissues, such as for instance as a consequence of increased cross-linking. Imputation of the protease activity based on directional changes in urinary collagen fragments might be incorrect. To account for this potential problem, we also performed a Proteasix analysis, excluding collagen fragments. 


\section{Results}

\section{Characteristics of patients}

The analysis included 998 survivors and 245 nonsurvivors. Nonsurvivors compared with survivors (Table 1) included more patients with diabetes mellitus $(26.5 \%$ vs. $14.5 \%)$ and needing dialysis (10.2 vs. 5.7\%). Nonsurvivors were older (68.9 vs. 57.2 years), had lower diastolic blood pressure (61.7 vs. $64.5 \mathrm{mmHg})$, mean arterial pressure (82.6 vs. $84.8 \mathrm{mmHg}$ ), lower eGFR $_{\text {crt }}$ $\left(80.1\right.$ vs. $\left.98.8 \mathrm{~mL} / \mathrm{min} / 1.73 \mathrm{~m}^{2}\right)$ and eGFR $_{\text {cys }}(48.3$ vs. $75.8 \mathrm{~mL} / \mathrm{min} / 1.73 \mathrm{~m}^{2}$ ), but higher Charlson Comorbidity Index (5 vs. 2 points; Table 1 ).

\section{Discovery and validation}

The characteristics of surviving and nonsurviving patients in the discovery and validation datasets were broadly similar (see Additional file 1: Tables S2 and S3 and Figure S1). The analysis of the discovery dataset (number of deaths/survivors, 70/299) enabled identification of 128 peptides, which were significantly associated with the 1-year post-ICU mortality. Of 63 peptides with sequence information available, 28 (44.4\%) were collagen fragments (Additional file 1: Table S5). The 128 peptides were combined in a multidimensional classifier, termed ACM128 (Additional file 1: Figure S1). With the C and

Table 1 Clinical characteristics at baseline by 1-year survival status

\begin{tabular}{|c|c|c|c|}
\hline Characteristic & Survivors ( $n=998$ ) & Nonsurvivors $(n=245)$ & $P$ value \\
\hline \multicolumn{4}{|l|}{$\mathrm{N}$ with characteristic (\%) } \\
\hline Women & $357(35.8)$ & $84(35.1)$ & 0.84 \\
\hline Diabetes mellitus & $145(14.5)$ & $65(26.5)$ & $<0.0001$ \\
\hline \multicolumn{4}{|l|}{ Indication of intensive care } \\
\hline Acute respiratory insufficiency & $198(19.8)$ & $63(25.7)$ & 0.043 \\
\hline Pancreatitis or liver failure & $14(1.4)$ & $8(3.3)$ & 0.048 \\
\hline Hemorrhagic or hypovolemic shock & $56(5.6)$ & $21(8.6)$ & 0.085 \\
\hline Cardiogenic shock or heart failure & $145(14.5)$ & $34(13.9)$ & 0.79 \\
\hline Sepsis or anaphylactic shock & $230(23.1)$ & $68(27.8)$ & 0.12 \\
\hline Post-surgical care & $101(10.1)$ & $23(9.4)$ & 0.73 \\
\hline Severe trauma & $78(7.8)$ & 0 & $<0.0001$ \\
\hline Other indications & $176(17.6)$ & $28(11.4)$ & 0.019 \\
\hline \multicolumn{4}{|l|}{ Treatment administered } \\
\hline Mechanical ventilation & $615(61.6)$ & $139(56.7)$ & 0.16 \\
\hline Extracorporeal membrane oxygenation & $9(0.9)$ & $1(0.4)$ & 0.44 \\
\hline Dialysis & $57(5.7)$ & $25(10.2)$ & 0.011 \\
\hline \multicolumn{4}{|l|}{ Mean characteristic (SD) } \\
\hline Age, years & $57.2(16.9)$ & $68.9(12.3)$ & $<0.0001$ \\
\hline Body mass index, $\mathrm{kg} / \mathrm{m}^{2}$ & $27.7(7.6)$ & $26.8(5.4)$ & 0.081 \\
\hline Systolic pressure, mmHg & $125.7(22.5)$ & $124.5(22.6)$ & 0.47 \\
\hline Diastolic pressure, mmHg & $64.5(14.0)$ & $61.7(13.1)$ & 0.0046 \\
\hline Mean arterial pressure, $\mathrm{mmHg}$ & $84.8(14.7)$ & $82.6(13.6)$ & 0.030 \\
\hline Heart rate, beats per minute & $92.5(20.7)$ & $89.4(19.7)$ & 0.033 \\
\hline Blood glucose, mmol/L & $7.35(2.33)$ & $7.65(2.70)$ & 0.22 \\
\hline $\mathrm{eGFR}_{\mathrm{crt}}, \mathrm{mL} / \mathrm{min} / 1.73 \mathrm{~m}^{2}$ & $98.8(55.6)$ & $80.1(57.9)$ & $<0.0001$ \\
\hline 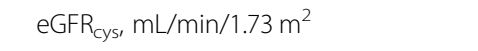 & $75.8(45.9)$ & $48.3(36.2)$ & $<0.0001$ \\
\hline \multicolumn{4}{|l|}{ Median characteristic (IQR) } \\
\hline Charlson Comorbidity Index & $2(1-4)$ & $5(3-6)$ & $<0.0001$ \\
\hline SOFA score & $7(4-10)$ & $8(5-10)$ & 0.46 \\
\hline Length of ICU stay, days & $11(7-18)$ & $12(7-22)$ & 0.092 \\
\hline
\end{tabular}

Baseline refers to the date of ICU admission. Body mass index was body weight in kilograms divided by height in meters squared. Mean arterial pressure is diastolic pressure plus one third of the difference between systolic and diastolic pressure. Diabetes mellitus was a fasting/random glucose $\geq 7.0 / 11.1 \mathrm{mmol} / \mathrm{L}$, use of anti-diabetic agents or a diagnosis in medical records. $P$ denotes the significance of the difference between survivors and nonsurvivors Abbreviations: $e G F R_{c r t} / e G F R_{\text {cys }}$ glomerular filtration rate derived from serum creatinine/cystatin C according to the Chronic Kidney Disease Epidemiology Collaboration equation (16), ICU intensive care unit, SOFA Sequential Organ Failure Assessment Score (15), IQR interquartile range 
gamma parameters set at 10,240 and 0.0000002 , respectively, the AUC was 0.755 (95\% confidence interval [CI], 0.708 to $0.798 ; P<0.0001)$ after complete take-one-out cross-validation. The unadjusted hazard ratio for a 1-SD increment in ACM128 was 4.55 (CI, 3.47-5.96; $P<$ 0.0001 ). In the test set (number of deaths/survivors, 175/ 699), the AUC was 0.688 (CI, 0.656 to $0.719 ; P<0.0001$ ) and the hazard ratio 2.27 (CI, 1.86-2.78; $P<0.0001$ ).

With the exception of urinary albumin $(P=0.69)$, all circulating (BNP, hsTnT, hsTnI, ADM, sSD2, and NGAL) and urinary biomarkers (NGAL and ACM128) had higher levels in nonsurvivors than survivors (Table 2). Most circulating and urinary biomarkers were correlated (see Additional file 1: Table S2). For ACM128, the correlation coefficients were not significant with urinary albumin $(r=0.038 ; P=0.18)$; the correlation coefficients of ACM128 with the other circulating and urinary biomarkers ranged from $0.19(P=0.0083)$ for hsTnI and sST2 to $0.45(P<0.0001)$ for plasma NGAL.

\section{Improvement of model performance}

In the whole study sample ( $n=1243), 245$ deaths occurred within 1 year after ICU discharge, yielding a death rate of 19.7 per 100 patient-years (CI, 19.5-19.9 patient-years). With adjustments applied for sex and age, the cumulative death rate increased across thirds of the ACM128 distribution (low vs. top third, 6.7 [CI, 6.4-7.0] vs. 36.2 [CI, 35.6-36.8] deaths per 100 patient-years). Further adjustment for the Charlson Comorbidity Index did not remove this gradient (Fig. 1).

The proportional hazard assumption was met. While adjusting for center $(n=15)$, sex, age, mean arterial pressure, eGFR cys, and diabetes mellitus (Table 3), the hazard ratio relating the risk of death to ACM128 (+ $1 \mathrm{SD}$ ) was 2.41 (CI, 2.00-2.91). With similar adjustments applied, the hazard ratio for the Charlson Comorbidity Index $(+$ 1 point) was 1.24 (CI, 1.16-1.32) and for urinary albu$\min (+1 \mathrm{SD}) 1.23$ (CI, 1.07-1.42). The hazard ratios for the circulating biomarkers (+ $1 \mathrm{SD})$ ranged from 1.09 (CI, 0.94-1.25) for sST2 to 1.39 (CI, 1.11-1.48) for ADM (Table 3). Substituting eGFR cys $_{\text {as }}$ covariable by eGFR $_{\text {crt }}$ or replacing the center adjustment by type of ICU ward (medical, surgical, or mixed) yielded highly consistent estimates of the hazard ratios.

Based on the results presented in Table 3, we carried the Charlson Comorbidity Index, the circulating biomarkers (except hsTnI and sST2), and urinary albumin through to further analyses (Table 4). We assessed model performance based on NRI, IDI, and $\triangle \mathrm{AUC}$ by adding ACM128 to a model accounting for center, the covariables, and including either the Charlson Comorbidity Index or a second biomarker (Table 5). Adding ADM128 to these models consistently $(P \leq 0.0001)$ increased NRI, NDI, and the AUC (Table 5). Replacing ACM128 by the SOFA score combined with the length of the ICU stay as an index of frailty did not increase the AUC (AUC, $0.74 ; P=0.31$ ).

\section{Single urinary peptides}

The analysis of 153 single urinary peptides with known amino-acid sequence and detectable in over $70 \%$ of patients enabled identification of 19 peptides, which were associated with the risk of death with adjustments applied for sex, age, mean arterial pressure, GFR $_{\mathrm{cys}}$, and diabetes mellitus and with significance levels corrected for multiple testing (Additional file 1: Table S7). The risk of death, expressed per 1-SD increment in the marker signal amplitude increased with 14 collagen alpha-1 (I) fragments $(1.20 \leq \mathrm{HR} \leq 1.50 ; \quad 0.0001 \leq P \leq 0.0050)$, three collagen alpha-1 (III) fragments $(1.19 \leq \mathrm{HR} \leq 1.28 ; 0.00017 \leq P \leq$

Table 2 Biomarkers at baseline by 1-year survival status

\begin{tabular}{llll}
\hline Biomarkers & $\begin{array}{l}\text { Survivors }(n=998) \\
\text { Median }(\mathrm{IQR})\end{array}$ & $\begin{array}{l}\text { Nonsurvivors }(n=245) \\
\text { Median }(\mathrm{IQR})\end{array}$ \\
\hline $\begin{array}{lll}\text { Circulating } \\
\text { BNP, pg/mL }\end{array}$ & & $P$ \\
hsTNT, pg/L & $106(34,302)$ & $251(98,763)$ & $<0.0001$ \\
hsTnl, pg/L & $32(12,90)$ & $44(19,177)$ & $<0.0001$ \\
ADM, nmol/L & $28(8,184)$ & $41(13,390)$ & 0.0006 \\
SST2, ng/mL & $50(29,92)$ & $82(42,143)$ & $<0.0001$ \\
NGAL, mg/mL & $281(163,501)$ & $376(205,848)$ & 0.0002 \\
Urinary & $148(81,304)$ & $272(128,528)$ & $<0.0001$ \\
Albuminuria, mg/L & & $386(293,461)$ & $<.69$ \\
NGAL, ng/mL & $381(300,467)$ & $200(46,902)$ & $<0.0001$ \\
ACM128 & $84(31,390)$ & $0.11(-0.34,0.69)$ & $<0.0001$ \\
\hline
\end{tabular}

Values are medians (interquartile range). $P$ denotes the significance of the difference between survivors and nonsurvivors Abbreviations: BNP brain natriuretic peptide, $h s T n T$ high-sensitive troponin $\mathrm{T}$, $h s T h /$ high-sensitive troponin I, ADM biologically active adrenomedullin, sST2 soluble ST2, NGAL neutrophil-gelatinase-associated lipocalin, ACM128 multidimensional urinary proteomic biomarker 


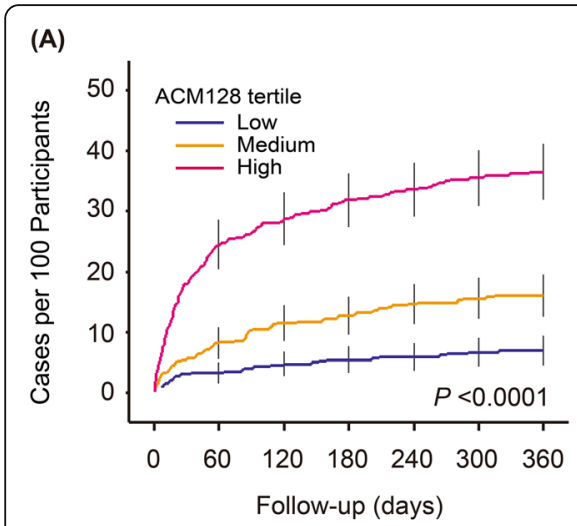

No. at risk

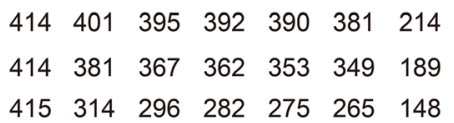

(B)

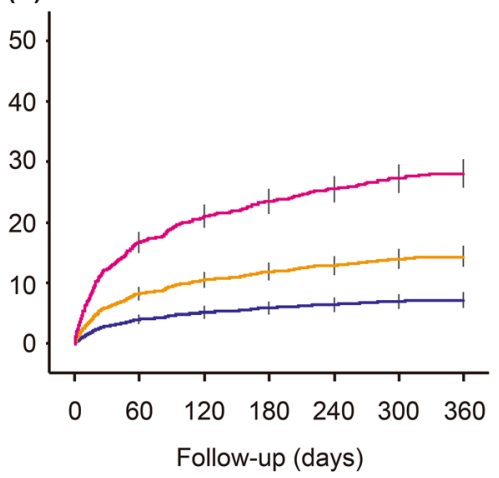

No. at risk

$\begin{array}{lllllll}414 & 401 & 395 & 392 & 390 & 381 & 214 \\ 414 & 381 & 367 & 362 & 353 & 349 & 189 \\ 415 & 314 & 296 & 282 & 275 & 265 & 148\end{array}$

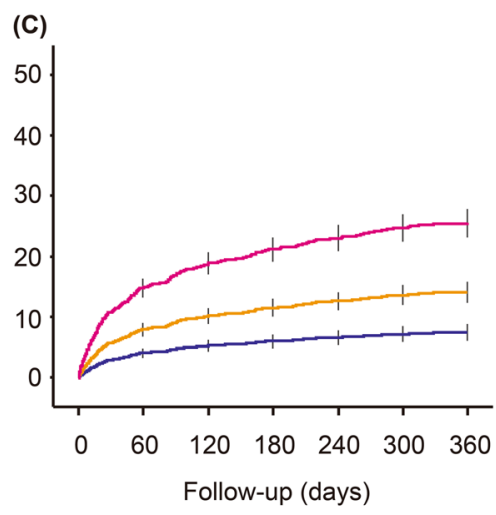

No. at risk

$\begin{array}{lllllll}414 & 401 & 395 & 392 & 390 & 381 & 214 \\ 414 & 381 & 367 & 362 & 353 & 349 & 189 \\ 415 & 314 & 296 & 282 & 275 & 265 & 148\end{array}$

Fig. 1 Cumulative incidence of mortality over 1 year in 1243 study participants by thirds of the ACM128 distribution, unadjusted (a), adjusted for sex and age (b), and additionally adjusted for Charlson Comorbidity Index (c). $P$ values denote the significance of the difference between the low $(\leq-0.662)$ and top (>-0.091) thirds of the ACM128 distribution. The numbers along the horizontal axis denote the number of patients at risk at 60-day intervals

0.0049), and one collagen alpha- 1 (V) chain (HR, 1.29; $P=$ 0.00014). The risk of death decreased with a fibrinogen alpha chain fragment $(\mathrm{HR}, 0.80 ; P=0.0013)$.

\section{Protease activity and pathway analysis}

The in silico analysis of sequenced urinary peptide fragments, including $(n=63)$ and excluding $(n=28)$ collagen, is presented in Additional file 1: Tables S6 and S7, respectively. With collagen fragments included, the proteases with a nonsurvivors-to-survivor ratio of 1.5 or greater included cathepsin E (1.98), D (1.89), G (1.70), S (1.52), and L1 (1.51), kallikrein-6 (1.77), and neutrophil elastase (1.67). The analysis with 28 collagen fragments excluded did not identify kallikrein-6, but was

Table 3 Hazard ratios expressing the risk of death in relation to risk factors and biomarkers in 1243 ICU survivors

\begin{tabular}{|c|c|c|}
\hline Risk factors & Hazard ratio $(95 \% \mathrm{Cl})$ & $P$ \\
\hline Number of deaths/number at risk & $245 / 1243$ & \\
\hline \multicolumn{3}{|l|}{ Clinical risk factors } \\
\hline Mechanical ventilation $(0,1)$ & $0.84(0.65,1.09)$ & 0.20 \\
\hline Sepsis $(0,1)$ & $0.99(0.74,1.32)$ & 0.92 \\
\hline Charlson Comorbidity Index (+ 1 point) & $1.24(1.16,1.32)$ & $<0.0001$ \\
\hline SOFA score (+ 1 point) & $0.99(0.86,1.15)$ & 0.92 \\
\hline Length of ICU stay (+ 1 day) & $1.18(1.03,1.34)$ & 0.014 \\
\hline \multicolumn{3}{|l|}{ Circulating biomarkers } \\
\hline $\mathrm{BNP}(+1 \mathrm{SD})$ & $1.38(1.19,1.60)$ & $<0.0001$ \\
\hline hsTNT (+ 1 SD) & $1.19(1.03,1.39)$ & 0.022 \\
\hline hsTnl (+ 1 SD) & $1.14(0.99,1.32)$ & 0.076 \\
\hline $\mathrm{ADM}(+1 \mathrm{SD})$ & $1.39(1.11,1.48)$ & 0.0006 \\
\hline sST2 (+ $1 \mathrm{SD})$ & $1.09(0.94,1.25)$ & 0.23 \\
\hline NGAL (+ $1 \mathrm{SD})$ & $1.28(1.11,1.47)$ & 0.0005 \\
\hline \multicolumn{3}{|l|}{ Urinary biomarkers } \\
\hline Albuminuria (+ 1 SD) & $1.23(1.07,1.42)$ & 0.0046 \\
\hline NGAL (+ 1 SD) & $1.13(0.98,1.31)$ & 0.094 \\
\hline ACM128 (+ 1 SD) & $2.41(2.00,2.91)$ & $<0.0001$ \\
\hline
\end{tabular}

Abbreviations of the biomarkers are given in Table 2. All models accounted for center $(n=15)$ as random effect and for sex, age, mean arterial pressure, glomerular filtration estimated from serum cystatin $C$, and diabetes mellitus 
Table 4 Hazard ratios expressing the risk of death in models adding ACM128 to an established risk factor or biomarker

\begin{tabular}{|c|c|c|c|c|}
\hline \multirow[t]{2}{*}{$\begin{array}{l}\text { Risk factor to which ACM128 } \\
\text { was added }\end{array}$} & \multicolumn{2}{|c|}{$\begin{array}{l}\text { Estimates for the risk factor to which ACM128 was } \\
\text { added }\end{array}$} & \multicolumn{2}{|c|}{$\begin{array}{l}\text { Estimates for ACM128 in models with a second risk factor } \\
\text { added }\end{array}$} \\
\hline & HR $(95 \% \mathrm{Cl})$ & $P$ & $\mathrm{HR}(95 \% \mathrm{Cl})$ & $P$ \\
\hline \multicolumn{5}{|l|}{ Clinical risk factors } \\
\hline Charlson Comorbidity Index & $1.20(1.12,1.28)$ & $<0.0001$ & $2.24(1.86,2.71)$ & $<0.0001$ \\
\hline Length of ICU stay & $1.12(0.99,1.27)$ & 0.078 & $2.38(1.97,2.87)$ & $<0.0001$ \\
\hline \multicolumn{5}{|l|}{ Circulating biomarkers } \\
\hline BNP & $1.15(0.99,1.34)$ & 0.070 & $2.28(1.87,2.77)$ & $<0.0001$ \\
\hline hsTnT & $1.03(0.87,1.20)$ & 0.76 & $2.40(1.98,2.91)$ & $<0.0001$ \\
\hline ADM & $1.06(0.91,1.23)$ & 0.46 & $2.35(1.93,2.87)$ & $<0.0001$ \\
\hline NGAL & $1.04(0.89,1.21)$ & 0.65 & $2.37(1.93,2.90)$ & $<0.0001$ \\
\hline \multicolumn{5}{|l|}{ Urinary biomarkers } \\
\hline Albumin & $1.14(0.99,1.32)$ & 0.078 & $2.37(1.96,2.86)$ & $<0.0001$ \\
\hline
\end{tabular}

Abbreviations of the biomarkers are given in Table 2 . The analysis includes 245 deaths and 1243 patients at risk. All models accounted for center ( $n=15$ ) as random effect and for sex, age, mean arterial pressure, glomerular filtration estimated from serum cystatin $\mathrm{C}$, and diabetes mellitus. Association sizes are expressed for a 1-SD increment in the biomarkers except for the Charlson Comorbidity Index (+ 1 point)

otherwise confirmatory, and additionally predicted matrix metalloproteinase 7 (1.51), 9 (1.61), 14 (1.90), and 25 (1.89), cathepsin B (1.82), S (1.79), and K (1.60), and meprin A subunit alpha (1.61).

The protein-protein interactome derived from 30 parental proteins identified from 63 sequenced urinary peptides included in the ACM128 classifier and the in silico predicted proteases (Additional file 1: Table S7) generated a network consisting of 57 nodes and 295 edges (Additional file 1: Figure S2), with a protein-protein interaction enrichment $P$ of 10-16. Excluding the 28 urinary collagen fragment from the Proteasix (Additional file 1: Table S8) and interactome analysis yielded a network of 37 nodes and 122 edges (Additional file 1: Figure S3) with an enrichment $P$ of 10-16. Both analyses revealed as top molecular pathways protein digestion and absorption (hsa04974), lysosomal activity (hsa04142), and apoptosis (hsa04210).

\section{Discussion}

In line with the recommendations of stakeholders [5, 7], the objective of the current study was to identify a urinary proteomic biomarker that may predict 1-year post-ICU mortality, thereby revealing molecular pathways contributing to prognosis. Pursuing this objective, we identified the multidimensional urinary biomarker ACM128, consisting of 128 dysregulated peptide fragments. In multivariableadjusted analyses, ACM128 measured at ICU admission predicted death within 1 year after ICU discharge with greater accuracy than clinical markers, such as the Charlson Comorbidity Index and the length of the ICU care, as well as other biomarkers tested within the context of post-ICU prognosis, including circulating BNP, hsTnT, active ADM and NGAL, and urinary albumin. Of note, the 1-year mortality was not significantly associated with circulating hsTnI, sST2, and urinary NGAL (Table 3).

Table 5 Improvement of model performance for adding ACM128 to an established risk factor or biomarker in 1243 ICU survivors

\begin{tabular}{lllll}
\hline Risk factor to which ACM128 was added & IDI $(95 \% \mathrm{Cl})$ & NRI $(95 \% \mathrm{Cl})$ & AUC of basic model $(95 \% \mathrm{Cl})$ & Increase in AUC by adding ACM128 \\
\hline $\begin{array}{l}\text { Clinical risk factors } \\
\quad \text { Charlson Comorbidity Index }\end{array}$ & $1.12(0.72,1.51)$ & $49.3(35.6,63.0)$ & $0.746(0.713,0.779)$ & $0.042(0.022,0.063)$ \\
$\quad$ ICU stay & $1.24(0.87,1.62)$ & $51.3(37.6,65.0)$ & $0.719(0.686,0.753)$ & $0.057(0.033,0.081)$ \\
Circulating biomarkers & & & & $0.048(0.026,0.069)$ \\
BNP & $1.12(0.76,1.47)$ & $41.0(27.2,54.8)$ & $0.726(0.693,0.759)$ & $0.056(0.032,0.080)$ \\
hsTnT & $1.23(0.85,1.60)$ & $47.9(34.1,61.6)$ & $0.718(0.684,0.752)$ & $0.049(0.028,0.071)$ \\
ADM & $1.14(0.78,1.50)$ & $52.8(39.2,66.4)$ & $0.724(0.691,0.757)$ & $0.045(0.023,0.066)$ \\
NGAL & $1.11(0.75,1.71)$ & $52.8(39.1,66.4)$ & $0.729(0.696,0.763)$ & $0.053(0.029,0.077)$ \\
Urinary albumin & $1.22(0.84,1.60)$ & $46.4(32.7,60.1)$ & $0.721(0.686,0.755)$ &
\end{tabular}

Abbreviations of the biomarkers are given in Table 2. The analysis includes 245 deaths and 1243 patients at risk. IDN indicates the integrated discrimination improvement, NRI the net reclassification improvement, and AUC to the area under the curve. All estimates, given with $95 \%$ confidence interval, were significant $(P \leq 0.0001)$. All models accounted for center $(n=15)$ as random effect and for sex, age, mean arterial pressure, estimated glomerular filtration estimated from serum cystatin $C$, and diabetes mellitus. The basic model included the covariables and the risk factor or biomarker to which ACM128 was added. IDI is the difference between the discrimination slopes of the basic model and the basic model extended with ACM128. The discrimination slope is the difference in predicted probabilities (\%) between cases and controls. NRI is the sum of the percent of patients reclassified correctly as cases and controls 
A PubMed search with search terms "Intensive Care" AND "Mortality" AND "Proteome" OR "Proteomics" yielded 15 hits, published from 2003 until 2018, without any relevance to the current manuscript. Replacing "Proteome" by "Biomarker" yielded 420 hits, with few focusing on the biomarkers reported in Table 3 and none on a multidimensional proteomic marker. Previously published studies reported on NGAL [27], ADM [28, 29], NT-proB-type natriuretic peptide (NT-proBNP) [30, 31], hsTnT [32, 33], hsTnI [34], or sST2 used in combination with other circulating biomarkers [35]. In patients after major non-cardiac surgery, early NGAL-based prediction of imminent acute kidney injury followed by implementation of KDIGO care bundle (https://kdigo.org/guidelines/acute-kidney-injury/) reduced the severity of kidney injury, postoperative creatinine increase, and the length of ICU and hospital stay [27]. Compared with urinary NGAL, plasma NGAL was a better predictor of an adverse outcome (Table 3). Our observation replicated findings in 110 patients admitted to intensive care after cardiac surgery with cardiopulmonary bypass [36] and in 50 patients admitted to intensive care because of acute kidney injury [37]. Circulating NGAL is freely filtered in the glomeruli and reabsorbed in the proximal tubule $[38,39]$. In response to kidney injury, NGAL expression is upregulated in particular in the distal tubules. However, NGAL passing the glomerular sieve and impaired proximal tubular reabsorption also contribute to the urinary NGAL level $[40,41]$. On the other hand, NGAL back leaking from the tubules into the circulation, the extra-renal synthesis of NGAL, and reduced glomerular filtration all impact on the plasma levels [40, 41]. Thus, the kinetics of plasma and urinary NGAL explain why there might be discrepancy in the predictive value of both biomarkers.

In surgical patients with sepsis, ADM indicated a higher need of vasopressor treatment and predicted mortality after 90 days [28]. NT-proBNP is commonly elevated on admission to intensive care, increases with severity of disease, and is an independent predictor of mortality [42]. NT-proBNP and hsTnT exhibit additive prognostic potential, which exceeds their individual value. This might be attributed to a difference in underlying pathophysiological mechanisms and synergy between risk factors [30]. Furthermore, one study demonstrated that hsTNT was the only independent predictor of 1-year mortality in patients with shock, whereas BNP or echocardiographic indexes had no prognostic value [32,33]. In patients with nontraumatic subarachnoid hemorrhage, hsTnI measured within $24 \mathrm{~h}$ after the event predicted the need for a higher inspiratory oxygen fraction [34]. HsTnI is also a sensitive, albeit unspecific marker of myocardial infarction. Our current findings move the field forward, because ACM128 was predictive of the 1-year mortality after ICU discharge, independent of the underlying condition requiring intensive care. Moreover, compared with the aforementioned biomarkers, ACM128 was a better prognosticator of death as evidenced by IDI, NRI, and $\triangle$ AUC. IDI and NRI thereby provided complementary information. Indeed, if addition of a biomarker to a model increases the predicted probability in cases, this is reflected by a significant increase in IDI. NRI indicates the extent by which a biomarker improves diagnostic accuracy [24].

Under physiological conditions, about $70 \%$ of the urinary proteome originates from the kidney and the urinary tract, while $30 \%$ is derived from plasma [43]. Approximately $60 \%$ of the total mass of urinary peptides and proteins consist of collagen fragments [44]. Interactome mapping, using parental proteins identified from sequenced peptides contained in ACM128 and the in silico predicted proteases, revealed as top deregulated pathways protein digestion and absorption, lysosomal activity, and apoptosis. Furthermore, there was limited overlap in the peptide fragments making up the ACM128 biomarker and those known to be associated with chronic kidney disease (the CKD273 panel) [45] or with coronary heart disease (the CAD238 panel) [46]. Thus, ACM128 does not merely reflect micro- or macro-vascular insult.

The analysis of sequenced peptides was collagendriven, as reflected by predicted proteases and proteins assigned to enriched pathways. While the reduced number of peptides resulted, as expected, in a decrease in the pathway coverage, we observed high consistency in the interactome results irrespective of whether collagen fragments were included or not, supporting the validity of the approach.

Urinary proteomic profiling is progressing to clinical application for detection, prevention, and early intervention in type 2 diabetic patients with silent renal dysfunction $[47,48]$ and in patients at risk of left ventricular dysfunction $[49,50]$. The multidimensional proteomic biomarker CKD273 (sensitivity/specificity $>90 \%$ ) predicts the 3-year risk of kidney disease 2 years earlier than microalbuminuria (70\%/45\%) and leads to substantial cost savings [51], to be confirmed by the PRIORITY results to be published later this year [52, 53]. HF1 encompasses 85 urinary peptides and predicts subclinical diastolic left ventricular dysfunction 5 years ahead of echocardiography, while NTproBNP or BNP are not diagnostic in asymptomatic patient at risk of heart failure $[49,50]$. Our current findings highlight the need for further research into the clinical application of urinary proteomic profiling in ICU patients to identify those in need of further diagnostic and therapeutic work-up. Urinary proteomic profiling might replace magnetic resonance imaging [54] or kidney biopsy to diagnose myocardial and renal fibrosis, respectively. Furthermore, from the therapeutic angle, intensive risk factor management and antifibrotic drug treatment, using aldosterone receptor inhibitors, such as spironolactone 
or eplerenone, or the novel nonsteroidal antimineralocorticoid finerenone [55], or the novel sacubitril/valsartan [56], are options.

\section{Strong points and limitations}

Strong points of the current study are its prospective design, the confirmation of the "a priori" hypothesis that multidimensional urinary biomarkers have clinical utility in risk stratification without the need to standardize for urinary volume or creatinine concentration. Patients randomly assigned to the discovery and test set (Additional file 1: Table S3) had similar characteristics. Our results replicate literature findings on atrial natriuretic peptides [30, 31], hsTnT [32, 33], active ADM [28, 29], and NGAL [27] and urinary albumin as predictors of outcome among ICU patients, but show that ACM128 outperforms all these markers in predicting 1-year mortality after ICU discharge. Notwithstanding these strengths, the current study must also be interpreted within the context of its limitations. First, we collected all-cause and not cause-specific mortality. However, all-cause mortality has the advantage that this outcome does not require any adjudication as causespecific mortality does. Second, our study combines data from patients admitted to the ICU, because of surgical, medical, or mixed indications. While this may be considered as a weakness, it also facilitates the generalizability of our results. Finally, although the ACM128 outperformed established risk factors and widely used risk scores including Charlson Comorbidity Index and SOFA score as well as circulating and urinary biomarkers, cost-effectiveness analyses still have to be done as a lead on to further studies paving the way for the clinical application of ACM128.

\section{Conclusions and perspectives}

The urinary proteomic classifier ACM128 predicts the 1year post-ICU mortality over and beyond clinical risk factors and other biomarkers and revealed as top molecular pathways, potentially contributing to a fatal outcome, protein digestion and absorption, lysosomal activity, and apoptosis. The way to clinical application will be long and involves determining and validating diagnostic thresholds of ACM128, constructing risk prediction models, and last but not the least, if the previous steps are taken successfully, a randomized clinical trial following the PRIORITY design $[52,53]$.

\section{Supplementary information}

Supplementary information accompanies this paper at https://doi.org/10. 1186/s13054-019-2686-0.

Additional file 1. Supplemental Methods. Sample Preparation and CEMS Analysis. Quality Control. Mass Spectrometric Data Processing. Support Vector Modelling. Sequencing of Polypeptides. References. Table S1. Weights of Comorbidities in the Charlson Comorbidity Index. Table S2. Correlation Coefficients between Biomarkers. Table S3. Clinical
Characteristics at Baseline by Study Group and Survival Status. Table S4. Biomarkers at Baseline by Study Group and Survival Status. Table S5. Sequenced Peptides Included in the All-Cause Mortality Predictor Peptide Panel. Table S6. Association of Death with Single Sequenced Urinary Peptides. Table S7. Proteasix Analysis Including Collagen Fragments. Table S8 Proteasix Analysis Excluding Collagen Fragments. Figure S1. Distributions of multidimensional urinary ACM128 in survivors (A, C) and nonsurvivors $(B, D)$ in the discovery and test datasets. Figure S2. Proteinprotein interactome derived from 63 sequenced urinary peptides, including collagen fragments, and the in-silico Proteasix analysis. Figure S3. Protein-protein interactome derived from 35 sequenced urinary peptides, excluding collagen fragments, and the in-silico Proteasix analysis.

\section{Abbreviations}

ADM: Biologically active adrenomedullin; AUC: Area under the curve; BNP: Brain natriuretic peptide; CCl: Charlson Comorbidity Index; eGFRcrt: Estimated glomerular filtration rate was derived from serum creatinine; eGFRcys: Estimated glomerular filtration rate was derived from serum cystatin C; FROG-ICU: The French and European Outcome Registry in Intensive Care Unit; hsTnl: High-sensitive troponin I; hsTnT: High-sensitive troponin T; ICD: International Classification of Diseases; ICU: Intensive care units; IDI: Integrated discrimination improvement; NGAL: Neutrophilgelatinase-associated lipocalin; NRI: Net reclassification improvement; NT proBNP: The N-terminal prohormone of brain natriuretic peptide; SOFA: The Sequential Organ Failure Assessment score; sST2: The interleukin 1 receptor family member soluble ST2

\section{Acknowledgements}

The authors gratefully acknowledge the clerical assistance of Vera De Leebeeck and Renilde Wolfs at the Studies Coordinating Centre in Leuven, Belgium.

The French and European Outcome Registry in Intensive Care Unit Study was supported by The Programme Hospitalier de la Recherche Clinique (AON 10-216) and by the Societé Française d' Anesthésie-Réanimation. The European Union (HEALTH-F7-305507 HOMAGE) and the European Research Council (Advanced Researcher grant 2011-294713-EPLORE and Proof-of-

Concept grant 713601-uPROPHET) and the European Research Area Net for Cardiovascular Diseases (JTC2017-046-PROACT) supported research at the Studies Coordinating Centre, Leuven, Belgium. The author acknowledges funding received from the European Society of Cardiology in form of an ESC Research Grant. Mosaiques-Diagnostics AG, Hannover, Germany, received support from the European Research Area Net forCardiovascular Diseases (JTC2017-046-PROACT).

The French and European Outcome Registry in Intensive Care Unit Investigators

Hôpital Lariboisière (Paris)—N Deye, C Fauvaux, A Mebazaa, C Damoisel, D Payen;

Hôpital Saint Louis (Paris) —E Azoulay, AS Moreau, L Jacob, O Marie; Hôpital Bichat (Paris)—M Wolf, R Sonneville, R Bronchard;

Hôpital Beaujon (Clichy)—I Rennuit, C Paugam;

Hôpital Cochin (Paris)—JP Mira, A Cariou, A Tesnières;

Hôpital Bicêtre (Le Kremlin-Bicêtre)—N Dufour, N Anguel, L Guérin, J Duranteau, C Ract;

CHU de Marseille (Marseille)—M Leone, B Pastène;

Hôpital Raymond Poincaré (Garches) —-T Sharshar, A Fayssoyl;

Hôpital Saint-Antoine_-JL Baudel, B Guidet;

Hôpital De La Pitié-Salpêtrière (Paris)—Q Lu, W Jie Gu, N Brechot, A Combes;

CHU Saint Eloi (Montpellier)—S Jaber, A Pradel, Y Coisel, M Conseil; Hôpital Ambroise Paré (Boulogne)—A Vieillard-Baron, L Bodson; CHU Carémeau (Nîmes) — JY Lefrant, L Elotmani, A Ayral, S Lloret; Hôpital Jean Minjoz (Besançon)—S Pily-Flouri, JB Pretalli;

Clinique Universitaire Saint-Luc (Belgium)_PF Laterre, V Montiel, MF Dujardin, C Berghe.

Authors' contributions

$H M, J A S, A M$, and ZYZ contributed to the study concept and design. MCF, $E B, E F, E G, A M$ contributed to the acquisition of data. ENK, AL, HM, JAS, AM, and $Z Y Z$ analyzed and interpreted the data. All authors critically revised the 
manuscript for important intellectual content. ENK, AL, WYY, ZYZ, LT and JAS contributed to the statistical analysis. HM and JAS provided administrative, technical, or material support. HM, JAS, AM, and ZYZ supervised the study. All authors approved the final manuscript.

\section{Funding}

The European Research Council (Proof-of-Concept Grant 713601-uPROPHET), the European Research Area Net for Cardiovascular Diseases (JTC2017-046PROACT), and the Fonds voor Wetenschappelijk Onderzoek Vlaanderen, Ministry of the Flemish Community, Brussels, Belgium (G.0881.13) currently support the Studies Coordinating Centre in Leuven.

\section{Availability of data and materials}

All data will be available pending the consent from the patients.

\section{Ethics approval and consent to participate}

The study complied with the Declaration of Helsinki for research in humans and was ethically approved by the Comité de Protection des Personnes, île de France IV, Paris, France (IRB n00003835) and the Commission d'éthique biomédicale hospitalo-facultaire de I'hôpital de Louvain, Brussels, Belgium (IRB nB403201213352).

\section{Consent for publication}

All authors believe that the manuscript represents valid work and have reviewed and approved the final version.

\section{Competing interests}

H.M. is the co-owner of Mosaiques Diagnostics. E.N-K and A.L. are employed by Mosaiques Diagnostics. All other authors declare that they have no competing interests.

\section{Author details}

${ }^{1}$ Mosaiques Diagnostics GmbH, Hannover, Germany. ${ }^{2}$ Studies Coordinating Centre, Research Unit Hypertension and Cardiovascular Epidemiology, KU Leuven Department of Cardiovascular Sciences, University of Leuven, Campus Sint Rafaël, Kapucijnenvoer 35, Box 7001, 3000 Leuven, Belgium. ${ }^{3}$ Department of Cardiology, Shanghai General Hospital, Shanghai Jiao Tong University School of Medicine, Shanghai, China. ${ }^{4}$ Department of Anesthesiology and Intensive Care, Saint Louis-Lariboisière - Fernand Widal University Hospital, Assistance Publique Hôpitaux de Paris, Paris, France. ${ }^{5}$ Université de Paris, Paris, France. ${ }^{6}$ INSERM UMR-S 942 - MASCOT, Paris, France. ${ }^{7}$ Cardiovascular Research Institute Maastricht, Maastricht University, Maastricht, the Netherlands.

Received: 28 July 2019 Accepted: 26 November 2019 Published online: 09 January 2020

\section{References}

1. Wunsch H, Guerra C, Barnato AE, Angus DC, Li G, Linde-Zwirble WT. Threeyear outcomes for Medicare beneficiaries who survive intensive care. J Am Med Assoc. 2010;303:849-56.

2. Keenan SP, Dodek P, Chan K, Hogg RS, Craib KJP, Anis AH, Spinelli JJ. Intensive care unit admission has minimal impact on long-term mortality. Crit Care Med. 2002;30:501-7.

3. Williams TA, Dobb GJ, Finn JC, Knuiman MW, Geelhoed E, Li K, Webb SAR. Determinants of long-term survival after intensive care. Crit Care Med. 2008; 36:1523-30.

4. Lim SS, Vos T, Flaxman AD, Danaei G, Shibuya K, Adair-Rohani H, Amann M, Anderson HR, Andrews KG, Aryee M, et al. A comparative risk assessment of burden of disease and injury attributable to 67 risk factors and risk factor clusters in 21 regions, 1990-2010 : a systematic analysis for the Global Burden of Disease Study 2010. Lancet. 2012;380:2224-60.

5. Angus DC, Carlet J, on behalf of the. Brussels Roundtable Participants: surviving intensive care: a report from the 2002 Brussels Roundtable. Intensive Care Med. 2002;2002(29):368-77.

6. Desai SV, Law TL, Needham DM. Long-term complications of critical care. Crit Care Med. 2011;39:371-9.

7. Needham DM, Davidson J, Cohen H, Hopkins RO, Weinert C, Wunsch H, Zawistowski C, Bernis-Dougherty A, Berney SC, Bienvenu J, et al. Improving long-term outcomes after discharge from intensive care unit: report from a stakeholders conference. Crit Care Med. 2012;40:502-9.
8. Gayat E, Cariou A, Deye N, Vieillard-Baron A, Jaber S, Damoisel C, Lu Q, Monnet X, Rennuit I, Azoulay E, et al. Determinants of long-term outcome in ICU survivors: results from the FROG-ICU study. Crit Care. 2018;22:8.

9. Mischak H, Vlahou A, loannidis JP. Technical aspects and inter-laboratory variability in native peptide profiling : the CE-MS experience. Clin Biochem. 2013;46:432-43.

10. Latosinska A, Siwy J, Mischak H, Frantzi M: Peptidomics and proteomics based on CE-MS as a robust tool in clinical application: the past, the present, and the bright future. Electrophoresis 2019, 40:doi: https://doi.org/ 10.1002/elps.201900091.

11. Mebazaa A, Casadio MC, Azoulay E, Guidet B, Jaber S, Levy B, Payen D, Vicaut E, Resche-Rigon M, Gayat E. Post-ICU discharge and outcome: rationale and methods of the The French and euRopean Outcome reGistry in Intensive Care Units (FROG-ICU) observational study. BMC Anesthesiol. 2015;15:143

12. Sternbach GL. The Glasgow Coma Scale. J Emerg Med. 2000;19:67-71.

13. Charlson ME, Pompei $P$, Ales KL, Mackenzie CR. A method of classifying prognostic comorbidity in longitudinal studies: development and validation. J Chron Dis. 1987:40:373-83.

14. Roffman CE, Buchanan J, Allison GT. Charlson Comorbidity Index. J Physiother. 2016:32:171.

15. Lopes Ferreira F, Bota DP, Bross A, Mélot C, Vincent JL. Serial evaluation of the SOFA score to predict outcome in critically ill patients. J Am Med Assoc. 2001;286:1754-8.

16. Inker LA, Schmid $\mathrm{CH}$, Tighiouart $H$, Eckfeldt JH, Feldman $H$ I, Greene T, Kusek JW, Manzi J, Van Lente F, Zhang YL, et al. Estimating glomerular filtration rate from serum creatinine and cystatin C. N Engl J Med. 2012;367:20-9.

17. de Lemos JA, Drazner MH, Omland T, Ayers CR, Khera A, Rohatgi A, Hashim I, Berry JD, Das SR, Morrow DA, et al. Association of troponin T detected with a highly sensitive assay and cardiac structure and mortality risk in the general population. JAMA. 2010;304:2503-12.

18. Gassenmaier T, Buchner S, Birner C, Jungbauer CG, Resch M, Debl K, Endemann DH, Riegger GA, Lehn P, Schmitz G, et al. High-sensitive troponin I in acute cardiac conditions: implications of baseline and sequential measurements for diagnosis of myocardial infarction. Atherosclerosis. 2012; 222:116-22.

19. Caironi P, Latini R, Struck J, Hartmann O, Bergmann A, Maggio A, Cavana M, Tognoni G, Pesenti A, Gattinoni L, et al. Circulating biologically active adrenomedullin (bio-ADM) predicts hemodynamic support requirement and mortality during sepsis. Chest. 2017;152:312-20.

20. Dieplinger B, Mueller T. Soluble ST2 in heart failure. Clin Chim Acta. 2015; 443:57-70.

21. Devarajan P. Neutrophil gelatinase-associated lipocalin (NGAL). Scand J Clin Lab Invest Suppl. 2008;241:89-94.

22. Mischak H, Kolch W, Aivalotis M, Bouyssie D, Court M, Dihazi H, Dihazi GH, Franke J, Garin J, Gonzalez de Peredo A, et al. Comprehensive human urine standards for comparability and standardization in clinical proteome analysis. Proteomics Clin Appl. 2010;4:464-78.

23. Blom G. Statistical estimates and transformed beta-variables. Biom J. 1961;3:285.

24. Pencina MJ, D'Agostino RB Sr, Steyerberg EW. Extensions of net reclassification improvement calculations to measure usefulness of new biomarkers. Stat Med. 2011;30:11-21.

25. Klein J, Eales J, Zürbig P, Vlahou A, Mischak H, Stevens R. Proteasix : a tool for automated and large-scale prediction of proteases involved in naturally occurring peptide generation. Proteomics. 2013;13:1077-82.

26. Arguello Casteleiro M, Klein J, Stevens R. The Proteasix ontology. J Biomed Semantics. 2016;7:33.

27. Göcze I, Jauch D, Götz M, Kennedy P, Jung B, Zeman F, Gnewuch C, Graf BM, Gnann W, Banas B, et al. Biomarker-guided intervention to prevent acute kidney injury after major surgery. The Prospective Randomized BigpAK Study. Ann Surg. 2018;267:1013-20.

28. Simon TP, Martin L, Doemming S, Humbs A, Bruells C, Kopp R, Hartmann O, Struck J, Bergmann A, Marx G, et al. Plasma adrenomedullin in critically ill patients with sepsis after major surgery : a pilot study. J Crit Care. 2017;38:68-72.

29. Mebazaa A, Geven C, Hollinger A, Wittebole X, Chousterman BG, Blet A, Gayat E, Hartmann O, Scigalla P, Bergmann A, et al. Circulating adrenomedullin estimates survival and reversibility of organ failure in sepsis : the prospective observational multinational Adrenomedullin and Outcome in Sepsis and Septic Shoch-1 (AdrenOSS-1) Study. Crit Care. 2019;22:354.

30. Lenz M, Krychtiuk KA, Goliasch G, Distelmaier K, Wojta J, Heinz G, Speidl WS. $\mathrm{N}$-terminal pro-brain natriuretic peptide and high-sensitivity troponin $\mathrm{T}$ 
exhibit additive prognostic value for the outcome of critically ill patients. Eur Heart J Acute Cardiovasc Care. 2018;2048872618768088.

31. Mehta C, Dara B, Mehta Y, Tariq A, Joby G, Singh M. Retrospective study on prognostic importance of serum procalcitonin and aminoterminal pro-brain natriuretic peptide levels as compared to Acute Physiology and Chronic Health Evaluation IV Score on intensive care unit admission in a mixed intensive care unit population. Ann Card Anaesth. 2016;19:256-62.

32. Bauzá-Martinez J, Aletti F, Pinto BB, Ribas V, Odena MA, Díaz R, Romay E, Ferrer R, Kistler EB, Tedeschi G, et al. Proteolysis in septic shock patients: plasma peptidomic patterns are associated with mortality. $\mathrm{Br} J$ Anaesth. 2018;121:1065-74.

33. Bergenzaun L, Öhlin H, Gudmundsson P, Düring J, Willenheimer R, Chew MS. High-sensitive cardiac troponin $T$ is superior to echocardiography in predicting 1-year mortality in patients with SIRS and shock in intensive care. BMC Anesthesiol. 2012;12:25.

34. Bender M, Stein M, Uhl E, Reinges MHT. Troponin I as an early biomarker of cardiopulmonary parameters within the first 24 hours after nontraumatic subarachnoid hemorrhage in intensive care unit patients. J Intensive Care Med. in press.

35. Dieplinger B, Egger M, Leitner I, Firlinger F, Poelz W, Lenz K, Haltmayer M, Mueller T. Interleukin 6 , galectin 3 , growth differentiation factor 15 , and soluble ST2 for mortality prediction in critically ill patients. J Crit Care. 2016; 34:38-45.

36. Mahmoodpoor A, Hamishehkar H, Fattah V, Sanaie S, Arora P, Nader ND. Urinary versus plasma neutrophil gelatinase-associated lipocalin (NGAL) as a predictor of mortality for acute kidney injury in intensive care unit patients. J Clin Anesth. 2018;44:12-7.

37. Schley G, Köberle C, Manuilova E, Rutz S, Forster C, Weyand M, Formentini I, Kientsch-Engel R, Eckardt KU, Willam C. Comparison of plasma and urine biomarker performance in acute kidney injury. PLoS One. 2015;10:e0145042.

38. Mori K, Lee HT, Rapoport D, Drexler IR, Foster K, Yang J, Schmidt-Ott KM, Chen X, Li JY, Weiss S, et al. Endocytic delivery of lipocalin-siderophore-iron complex rescues the kidney from ischemia-reperfusion injury. J Clin Invest. 2005;115:610-21.

39. Hvidberg V, Jacobsen C, Strong RK, Cowland JB, Moestrup SK, Borregaard N. The endocytic receptor megalin binds the iron transporting neutrophilgelatinase-associated lipocalin with high affinity and mediates its cellular uptake. FEBS Lett. 2005;579:773-7.

40. Schmidt-Ott KM. Neutrophil gelatinase-associated lipocalin as a biomarker of acute kidney injury--where do we stand today? Nephrol Dial Transplant. 2011;26:762-4.

41. Haase M, Mertens PR, Haase-Fielitz A. Renal stress in vivo in real-time-visualised by the NGAL reporter mouse. Nephrol Dial Transplant. 2011;26: 2109-11.

42. De Geer L, Fredrikson M, Oscarsson A. Amino-terminal pro-brain natriuretic peptide as predictor of outcome in patients admitted to intensive care. A prospective observational study. Eur J Anaesthesiol. 2012;29:275-9.

43. Pieper R, Gatlin CL, McGrath AM, Makusky AJ, Mondal M, Seonarain M, Field E, Schatz CR, Estock MA, Ahmed N, et al. Characterization of the human urinary proteome : a method for high-resolution display of urinary proteins on two-dimensional electrophoresis gels with a yield of nearly 1400 distinct protein spots. Proteomics. 2004:4:1159-74.

44. Coon JJ, Zürbig P, Dakna M, Dominiczak AF, Decramer S, Fliser D, Frommberger M, Golovko I, Good DM, Herget-Rosenthal S, et al. CE-MS analysis of the human urinary proteome for biomarker discovery and disease diagnostics. Proteomics Clin Appl. 2008;2:964-73.

45. Good DM, Zürbig P, Argilés A, Bauer HW, Behrens G, Coon JJ, Dakna M, Decramer S, Delles C, Dominiczak AF, et al. Naturally occurring human urinary peptides for use in diagnosis of chronic kidney disease. Mol Cell Proteomics. 2010;9:2424-37.

46. Delles $C$, Schiffer E, von Zur MC, Peter K, Rossing P, Parving HH, Dymott JA, Neisius U, Zimmerli LU, Snell-Bergeon JK, et al. Urinary proteomic diagnosis of coronary artery disease: identification and clinical validation in 623 individuals. J Hypertens. 2010;28:2316-22.

47. Gu YM, Thijs L, Liu YP, Zhang ZY, Jacobs J, Koeck T, Zürbig P, Lichtinghagen $\mathrm{R}$, Brand $\mathrm{K}$, Kuznetsova $\mathrm{T}$, et al. The urinary proteome as correlate and predictor of renal function in a population study. Nephrol Dial Transplant. 2014;29:2260-8

48. Pontillo C, Zhang ZY, Schanstra JP, Jacobs L, Zürbig P, Thiis L, RamirezTorres A, Heerspink HJL, Lindhardt M, Klein R, et al. Prediction of chronic kidney disease stage 3 by CKD273, a urinary proteomic biomarker. KI Reports. 2017;2:1066-75.

49. Kuznetsova T, Mischak H, Mullen W, Staessen JA. Urinary proteome analysis in hypertensive patients with left ventricular diastolic dysfunction. Eur Heart J. 2012;33:2342-50.

50. Zhang ZY, Nkuipou-Kenfack E, Yang WY, Wei FF, Cauwenberghs N, Thijs L, Huang QF, Feng YM, Schanstra JP, Kuznetsova T, et al. Epidemiologic observations guiding clinical application of the HF1 urinary peptidomic marker of diastolic left ventricular dysfunction. J Am Soc Hypertens. 2018;12:438-47.

51. Critselis E, Vlahou A, Stel VS, Morton RL. Cost-effectiveness of screening type 2 diabetes patients for chronic kidney disease progression with the CKD273 urinary peptide classifier as compared to urinary albumin excretion. Nephrol Dial Transplant. 2018;33:441-9.

52. Lindhardt M, Persson F, Currie G, Pontillo C, Beige J, Delles C, von der Leyen $H$, Mischak H, Navis G, Noutsou M, et al. Proteomic prediction and renin angiotensin aldosterone system inhibition prevention of early diabetic nephropathy in type 2 diabetic patients with normoalbuminuria (PRIORITY) : essential study design and rationale of a randomised clinical multicentre trial. Br Med J Open. 2016;2016:e010310.

53. Tofte N, Lindhardt M, Adamova K, Beige J, Beulens JWJ, Birkenfeld AL, Currie G, Delles C, Dimos I, Francová L, et al. Characteristics of high- and low-risk individuals in the PRIORITY study: urinary proteomics and mineralocorticoid receptor antagonism for prevention of diabetic nephropathy in type 2 diabetes. Diabet Med. 2018;35:1375-82.

54. Zannad $\mathrm{F}$. What is measured by cardiac fibrosis biomarkers and imaging? Circ Heart Fail. 2014;7:239-42.

55. Pei H, Wang W, Zhao D, Wang L, Su GH, Zhao Z. The use of novel nonsteroidal mineralocorticoid receptor antagonist finerenone for the treatment of chronic heart failure. A systematic review and meta-analysis. Medicine (Baltimore). 2018;97:e0254.

56. Burke RM, Lighthouse JK, Mickelsen DM, Small EM. Sacubitril/valsartan decreases cardiac fibrosis in left ventricle pressure overload by restoring PKG signaling in cardiac fibroblasts. Circ Heart Fail. 2019;12:e005565.

\section{Publisher's Note}

Springer Nature remains neutral with regard to jurisdictional claims in published maps and institutional affiliations.
Ready to submit your research? Choose BMC and benefit from:

- fast, convenient online submission

- thorough peer review by experienced researchers in your field

- rapid publication on acceptance

- support for research data, including large and complex data types

- gold Open Access which fosters wider collaboration and increased citations

- maximum visibility for your research: over $100 \mathrm{M}$ website views per year

At BMC, research is always in progress.

Learn more biomedcentral.com/submissions 